\title{
Chapter 2 \\ Recent Progress in Research and Development in Neutron Resonance Densitometry (NRD) for Quantification of Nuclear Materials in Particle-Like Debris
}

\author{
M. Koizumi, F. Kitatani, H. Tsuchiya, H. Harada, J. Takamine, M. Kureta, \\ H. Iimura, M. Seya, B. Becker, S. Kopecky, W. Mondelaers, \\ and P. Schillebeeckx
}

\begin{abstract}
To quantify special nuclear materials (SNM) in particle-like debris, a technique named neutron resonance densitometry (NRD) has been proposed. This method is a combination of neutron resonance transmission analysis (NRTA) and neutron resonance capture analysis (NRCA) or prompt gamma-ray analysis (PGA). In NRTA, neutron transmission rate is measured as a function of neutron energy with a short flight path time-of-flight (TOF) system. Characteristic neutron transmission dips of $\mathrm{Pu}$ and $\mathrm{U}$ isotopes are used for their quantification. Materials in the samples (H, B, Cl, Fe, etc.) are measured by the NRCA/PGA method. For the NRD measurements, a compact TOF facility is designed. The statistical uncertainties of the obtained quantities of the SNMs in a sample are estimated. A high-energyresolution and high-S/N $\gamma$-ray spectrometer is under development for NRCA/PGA. Experimental studies of systematic uncertainties concerning the sample properties, such as thickness and uniformity, are in progress at the TOF facility GELINA of European Commission (EC), Joint Research Centre (JRC), Institute for Reference Materials and Measurements (IRMM).
\end{abstract}

Keywords Capture - Fukushima - GELINA • Neutron resonance densitometry - NRD • Nuclear security $\bullet$ Severe accident $\bullet$ Transmission

\footnotetext{
M. Koizumi $(\bowtie) \cdot$ F. Kitatani $\bullet$ H. Tsuchiya $\bullet$ H. Harada • J. Takamine $・$ M. Kureta $\bullet$ H. Iimura Nuclear Science and Engineering Center, Japan Atomic Energy Agency, Tokai-mura,

Naka-gun, Ibaraki 319-1195, Japan

e-mail: koizumi.mitsuo@jaea.go.jp

M. Seya

Integrated Support Center for Nuclear Nonproliferation and Nuclear Security, Japan Atomic Energy Agency, Tokai-mura, Naka-gun, Ibaraki 319-1118, Japan

B. Becker • S. Kopecky • W. Mondelaers • P. Schillebeeckx

European Commission, Joint Research Centre, Institute for Reference Materials and Measurements, Retieseweg 111, 2440, Geel, Belgium
} 


\subsection{Introduction}

Quantifying nuclear materials (NM) in the debris of melted fuel (MF) formed in a severe accident is considered to be difficult because of their variety of size, shape, unknown composition, and strong radioactivity. Although techniques of nondestructive assay (NDA) are indispensable for the evaluation of NM in debris, quantification methods have not been established so far [1]. In the cases of TMI-2 or Chernobyl-4, accounting for the NM was based on some estimations.

We have proposed a technique called neutron resonance densitometry (NRD) $[2,3]$ to quantify NM in particle-like debris that is assumed to be produced in the rapid cooling processes of a severe accident [4]. Small pieces are also produced when MF are cut or broken down to be taken out of the damaged reactors [1].

To examine the NRD method, studies have begun. Some experiments were carried out at the time-of-flight (TOF) facility GELINA [5] of EC-JRC-IRMM under the agreement between JAEA and EURATOM in the field of nuclear materials safeguards research and development.

In this chapter, we briefly describe the concept of NRD, give an overview of the development of NRD, and explain some parts of the recent progress.

\subsection{Neutron Resonance Densitometry}

\subsubsection{The Concept of NRD}

Neutron resonance densitometry is a method of a combination of neutron resonance transmission analysis (NRTA) and neutron resonance capture analysis (NRCA) or prompt gamma-ray analysis (PGA). The fundamental principles of NRTA and NRCA are described by Postma and Schillebeeckx [6].

In NRTA, neutron transmission is measured as a function of neutron energy with a TOF technique. Characteristic neutron transmission dips of $\mathrm{Pu}$ and $\mathrm{U}$ isotopes are observed in the neutron energy in the range of $1-50 \mathrm{eV}[7,8]$. Measurements of these transmission spectra can be carried out with a short-flight path TOF system $[9,10]$.

Although strong $\gamma$-ray radiation from MF samples does not interfere with NRTA measurements, reduction of neutron flux caused by nuclei with large total cross section (such as $\mathrm{H}, \mathrm{B}, \mathrm{Cl}, \mathrm{Fe}$ ) makes accurate NM quantification difficult. Nevertheless, the quantities of these contained nuclei could not be determined by NRTA only, because these nuclei do not resonantly interact with neutrons in this energy range. To identify and to quantity the composing isotopes, the NRCA/PGA method is required. Characteristic prompt $\gamma$ rays ware utilized. Table 2.1 shows prompt $\gamma$-rays emitted from nuclei after neutron capture reaction. Most of these discrete prompt $\gamma$-rays have significant intensities. The information obtained by NRCA/PGA enables us to determine the appropriate sample thickness and measurement time. This information also supports NRTA analysis. 
Table 2.1 Energies of prominent prompt $\gamma$-rays and the first neutron resonances of nuclei

\begin{tabular}{l|l|c|c}
\hline Nucleus & Reaction & Prompt $\gamma$ rays $(\mathrm{KeV})$ & First resonance $(\mathrm{KeV})$ \\
\hline${ }^{1} \mathrm{H}$ & ${ }^{1} \mathrm{H}(n, \gamma){ }^{2} \mathrm{H}$ & 2,223 & - \\
\hline${ }^{10} \mathrm{~B}$ & ${ }^{10} \mathrm{~B}(n, \alpha \gamma){ }^{7} \mathrm{Li}$ & 478 & 170 \\
${ }^{27} \mathrm{Al}$ & ${ }^{27} \mathrm{Al}(n, \gamma){ }^{28} \mathrm{Al}$ & $3,034,7,724$ & 5.9 \\
${ }^{28} \mathrm{Si}$ & ${ }^{28} \mathrm{Si}(n, \gamma){ }^{29} \mathrm{Si}$ & $3,539,4,934$ & 31.7 \\
\hline${ }^{53} \mathrm{Cr}$ & ${ }^{53} \mathrm{Cr}(n, \gamma){ }^{54} \mathrm{Cr}$ & $835,8,885$ & 4.2 \\
\hline${ }^{56} \mathrm{Fe}$ & ${ }^{56} \mathrm{Fe}(n, \gamma){ }^{57} \mathrm{Fe}$ & $7,631,7,646$ & 1.1 \\
\hline${ }^{59} \mathrm{Co}$ & ${ }^{59} \mathrm{Co}(n, \gamma){ }^{60} \mathrm{Co}$ & $230,6,877$ & 0.132 \\
\hline${ }^{58} \mathrm{Ni}$ & ${ }^{58} \mathrm{Ni}(n, \gamma){ }^{59} \mathrm{Ni}$ & $465,8,999$ & 6.9 \\
\hline
\end{tabular}

Fig. 2.1 A rough draft of an NRD facility. The neutron flight path length for NRTA is $5 \mathrm{~m}$ and that for NRCA/PGA is $2 \mathrm{~m}$

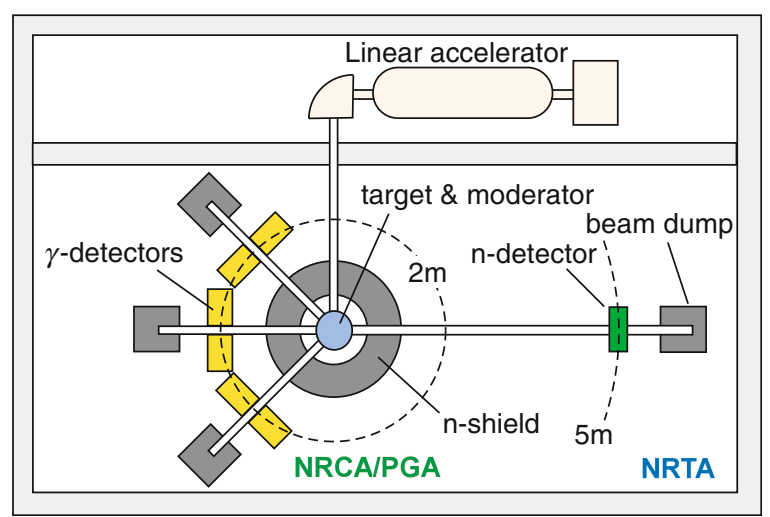

\subsubsection{A Rough Draft of an NRD Facility}

For practical application, the scale of an NRD facility should be minimized. Figure 2.1 shows a rough draft of the NRD facility. An electron linear accelerator with a power of $1 \mathrm{~kW}$ and acceleration voltage of $30 \mathrm{MeV}$ is assumed [11]. High-energy neutrons are generated in the order of $10^{12} \mathrm{n} / \mathrm{s}$ by photonuclear reactions following Bremsstrahlung at the electron target. The generated neutrons are slowed down to epithermal energy by collisions in a moderator surrounding the target. Neutrons from the moderator are collimated to supply for NRTA and for NRCA/PGA.

The length of the flight path is important to design a TOF system, because the longer flight path reduces the neutron flux whereas it increases the energy resolution of the system. It may require at least a 5-m flight path to achieve a good enough resolution to resolve resonances of NMs below $50 \mathrm{eV}$ in NRTA [9, 10]. A shorter neutron flight path is feasible for NRCA/PGA because the nuclei in Table 2.1 are identified by the prompt $\gamma$-ray energies. We consider that a $2-\mathrm{m}$ flight path is sufficient for NRCA/PGA. The beam line lengths mainly determine the scale of 
Table 2.2 Estimated statistical uncertainty of quantities of $U$ and Pu isotopes in a sample

\begin{tabular}{l|c|l}
\hline Nucleus & Concentration in a fuel $(\mathrm{kg} / \mathrm{tHM})$ & Statistic error $(\%)$ \\
\hline${ }^{238} \mathrm{Pu}$ & 0.19 & 0.85 \\
\hline${ }^{239} \mathrm{Pu}$ & 5.25 & 0.074 \\
${ }^{240} \mathrm{Pu}$ & 2.13 & 0.051 \\
${ }^{241} \mathrm{Pu}$ & 1.23 & 0.23 \\
\hline${ }^{242} \mathrm{Pu}$ & 0.48 & 0.069 \\
${ }^{235} \mathrm{U}$ & 14.6 & 0.049 \\
${ }^{238} \mathrm{U}$ & 928 & 0.010
\end{tabular}

The measurements are assumed to be carried out for $40 \mathrm{~min}$ with a $10^{12} \mathrm{n} / \mathrm{s}$ neutron source

the facility. One beam line for NRTA and three beam lines for NRCA/PGA are placed as shown in Fig. 2.1. The sample size for NRTA is assumed to be 10-30 cm in diameter and 1-2 cm in thickness. In comparison, the sample size for NRCA/ PGA is smaller; the diameter is $1-2 \mathrm{~cm}$, and the thickness is $1-2 \mathrm{~cm}$. A collimator is placed between the NRCA/PGA sample and the $\gamma$-ray detector to reduce the background $\gamma$-rays from the sample. Because optimal sample thickness for NRTA strongly depends on the amount of impurities or matrix material, the quantity of the interfering nuclei in debris has to be measured roughly by NRCA/PGA preceding NRTA measurements [12].

The statistical uncertainties of NMs quantified by NRTA were estimated [12]. The size of a MF sample is assumed to be $1 \mathrm{~cm}$ in thickness and $30 \mathrm{~cm}$ in diameter. The weight of the sample becomes about $4 \mathrm{~kg}$ : it consisted of nuclear fuel (64 vol.\%), ${ }^{\text {nat }} \mathrm{Fe}(8 \mathrm{vol} . \%),{ }^{\text {nat }} \mathrm{B}(8 \mathrm{vol} . \%)$, and $20 \mathrm{vol} . \%$ of vacancy. The composition of the nuclear fuel was taken from Ando and Takano [13] [a fuel of $40 \mathrm{GWd} / \mathrm{t}$ burn-up in a boiling water reactor (BWR)]. The measurement was assumed to be carried out for $40 \mathrm{~min}$, in which $20 \mathrm{~min}$ was for sample and $20 \mathrm{~min}$ for background. Table 2.2 shows the estimated statistical uncertainties of quantified $\mathrm{Pu}$ and $\mathrm{U}$ isotopes in the sample. The achieved statistical uncertainties are less than $1 \%$.

With the measurement cycle given here, about 0.15 ton of debris can be handled in a day; this enables us to measure 30 tons of debris in a year (200 working-days are assumed). This amount can be increased with the number of NRTA beam lines.

\subsection{Development of a $\gamma$-Ray Spectrometer for NRCA/PGA}

The $\gamma$-ray background from debris is expected to be strong. The strongest radioactive isotope in a MF of the TMI- 2 accident was ${ }^{137} \mathrm{Cs}$, which ranged from $10^{6}$ to $3 \times 10^{8} \mathrm{~Bq} / \mathrm{g}$ [14]. The energies of the prominent $\gamma$ rays from nuclei listed in Table 2.1 is larger than the $661 \mathrm{keV} \gamma$-rays from ${ }^{137} \mathrm{Cs}$, except for ${ }^{10} \mathrm{~B}$. Accordingly, most of the measurements of the NRCA/PGA will not have interference with the $\gamma$-rays from ${ }^{137} \mathrm{Cs}$. On the other hand, the Compton edge of the $661 \mathrm{keV} \gamma$-rays surely overlaps with the $478-\mathrm{keV} \gamma$-ray peak originating the $\left.{ }^{10} \mathrm{~B}(n, \alpha \gamma)\right)^{7} \mathrm{Li}$ reaction. 


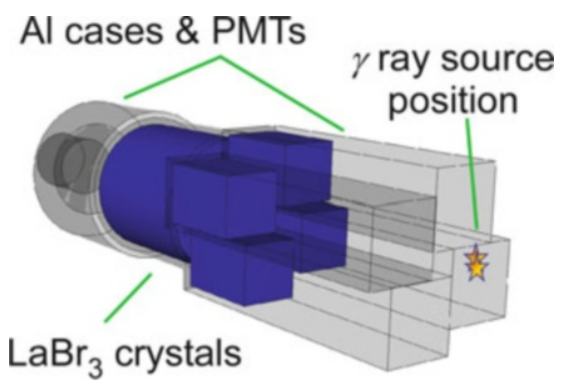

Fig. 2.2 Design of a prototype $\mathrm{LaBr}_{3} \gamma$-ray spectrometer, which consists of a cylindrical detector and four square pillar detectors. Collimated $\gamma$-rays pass through the square opening of the spectrometer to reach the cylindrical detector

The $\gamma$-ray spectrometer used for NRCA/PGA, therefore, requires properties of not only high-energy resolution and fast timing response, but also a high peak-toCompton ratio.

To satisfy these requirements, a well-type spectrometer made of $\mathrm{LaBr}_{3}$ crystal has been proposed $[2,15]$. In a study based on Monte Carlo simulations of a welltype $\mathrm{LaBr}_{3}$ spectrometer $[15,16]$, the Compton edge was successfully reduced by an order of magnitude. Such reduction enables us to roughly quantify ${ }^{10} \mathrm{~B}$ in a sample, even in the presence of high background $\gamma$-rays from ${ }^{137} \mathrm{Cs}$.

A prototype $\mathrm{LaBr}_{3} \gamma$-ray spectrometer has been designed (Fig. 2.2). Because of the technical difficulty of producing a crystal with a well, the spectrometer is made of several detectors: a cylindrical detector and four square pillar detectors. The cylindrical crystal is $120 \mathrm{~mm}$ in diameter and $127 \mathrm{~mm}$ in length; each square pillar crystal is $50.8 \times 50.8 \times 76.2 \mathrm{~mm}$. An arrangement of the detector pillars opens a square channel of $20 \times 20 \mathrm{~mm}$ for the passage of collimated $\gamma$-rays from the samples. This spectrometer will be tested soon.

\subsection{Experiments for NRD Developments}

To evaluate systematic uncertainties in NRD, we have started experimental study at GELINA [5] under the collaboration between JAEA and EC-JRC-IRMM. The items to be studied are as follows: (1) particle size, (2) sample thickness, (3) presence of contaminated materials, (4) sample temperature, and (5) the response of the TOF spectrometer [3, 17]. Some experiments has been performed at GELINA [18-21]. A resonance shape analysis code, REFIT [22], has been adopted for the data analysis.

Experiments on sample thickness were carried out at the 25-m TOF neutron beam line of GELINA. Cu plates with various thicknesses were measured with an NRTA method. Peaks at the $579 \mathrm{eV}$ resonance of ${ }^{63} \mathrm{Cu}$ were analyzed with the REFIT program. The evaluated areal densities are compared with the declared values, which were derived from measurements of the weight and the area of the 


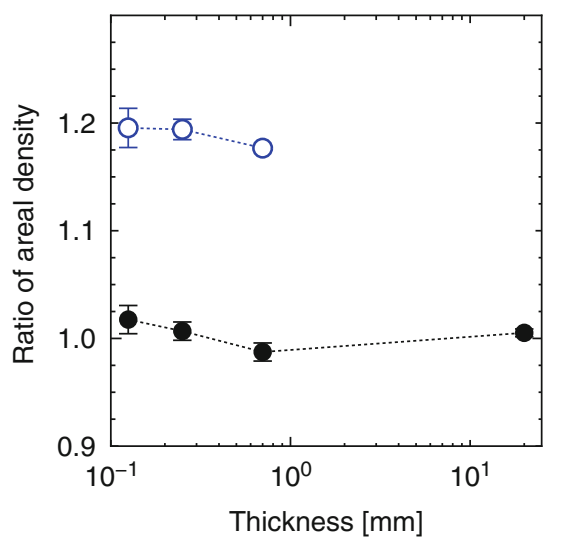

Fig. 2.3 Ratios of evaluated and declared areal densities. The $579 \mathrm{eV}$ transmission peaks of ${ }^{63} \mathrm{Cu}$ were analyzed with REFIT. Open circles indicate the results analyzed with the resonance parameter values taken from Mughabghab [23] (\#6 in Fig. 2.4), and closed circles represent tentatively introduced values (\#7 in Fig. 2.4), which reproduce the areal densities of $\mathrm{Cu}$ plates better. The lines are guides for the eye. Note: We also analyzed the transmission spectrum of a 2-cm-thick copper sample with the parameter \#6. The obtained fitted curve, however, did not reproduce the peak shape at all. Thus, the misleading open circle data point was removed
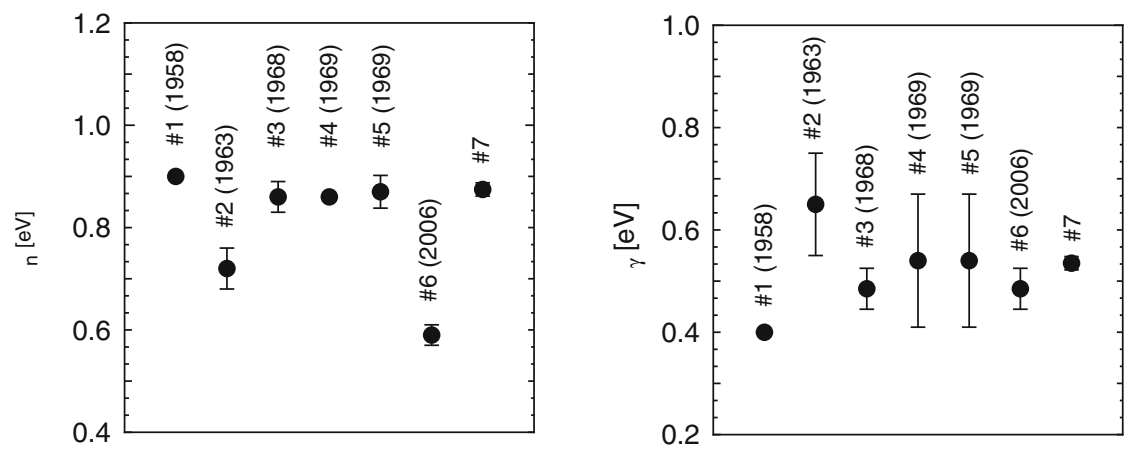

Fig. 2.4 Experimentally obtained $579 \mathrm{eV}^{63} \mathrm{Cu}$ resonance parameters. Each data point is taken from different references (\#1 [24], \#2 [25], \#3 [26], \#4 [27], \#5 [28], and \#6 [23]). The data of \#6 were utilized by REFIT originally; the data of \#7 are tentatively introduced to reproduce the experimental transmission dips

samples. Figure 2.3 shows the results. The abscissa is the thickness of the Cu plates and the ordinate is the ratio of evaluated and declared areal densities. The open circles are the results analyzed with the resonance parameter values taken from Mughabghab [23] (\#6 of Fig. 2.4); the closed circles are the results analyzed with the tentatively introduced values (\#7 of Fig. 2.4), which reproduced the areal density of $\mathrm{Cu}$ plates better. Figure 2.4 shows measured ${ }^{63} \mathrm{Cu}$ resonance parameters. The $579-\mathrm{eV}$ resonance parameters of ${ }^{63} \mathrm{Cu}$ may require being reevaluated. It should be emphasized that survey of the total cross sections of $\mathrm{Pu}$ and $\mathrm{U}$ isotopes is quite important to quantify NM. 


\subsection{Summary}

We have proposed NRD for measurements of NM in particle-like debris of MF. The NRD system utilizes a compact neutron TOF system equipped with a neutron detector for NRTA and high-energy-resolution and high-S/N $\gamma$-ray detectors for NRCA/PGA. The rough design of a NRD facility is given. The capacity of NM measurements in the facility has been shown. Experiments on systematical uncertainties caused by sample properties, such as sample thickness and uniformity, are in progress under the collaboration between JAEA and EC-JRC-IRMM. The importance of confirmation of nuclear data has been shown in the case of $\mathrm{Cu}$ thickness measurements by NRTA.

Acknowledgments The research and development have been carried out under the agreement between JAEA and EURATOM in the field of nuclear materials safeguards research and development and are supported by the Japanese government, the Ministry of Education, Culture, Sports, Science and Technology in Japan (MEXT).

Open Access This chapter is distributed under the terms of the Creative Commons Attribution Noncommercial License, which permits any noncommercial use, distribution, and reproduction in any medium, provided the original author(s) and source are credited.

\section{References}

1. Seya M, Harada H, Kitatani F, Koizumi M, Tsuchiya H, Iimura H, Kureta M, Takamine J, Hajima R, Hayakawa T, Shizuma T, Angell C, Bolind AM (2013) In: Proceedings of the INMM 54th annual meeting. The Institute of Nuclear Materials Management (INMM), Chicago, USA

2. Koizumi M, Kitatani F, Harada H, Takamine J, Kureta M, Seya M, Tsuchiya H, Iimura H (2012) In: Proceedings of the 53th INMM annual meeting. The Institute of Nuclear Materials Management (INMM), Chicago, USA

3. Harada H, Kitatani F, Koizumi M, Tsuchiya H, Takamine J, Kureta M, Iimura H, Seya M, Becker B, Kopecky S, Schillebeeckx P (2013) In: Proceedings of the 35th ESARDA. The Institute of Nuclear Materials Management (INMM), Chicago, USA

4. Watari T, Inoue Y, Masuda F (1990) J Atom Energy Soc Jpn 32:12-24 (in Japanese)

5. Mondelaers W, Schillebeecks P (2006) Notiziario 11:19-25

6. Postma H, Schillebeeckx P (2009) Neutron resonance capture and transmission analysis. In: Meyers RA (ed) Encyclopedia of analytical chemistry. Wiley, New York, pp 1-22

7. Bowman CD, Schrack RA, Behrens JW, Johnson RG (1983) Neutron resonance transmission analysis of reactor spent fuel assemblies. In: Barton JP, von der Hardt P (eds) Neutron radiography. ECSC/EEC/EAEC, Brussels/Belgium/Luxembourg, pp 503-511

8. Behrens JW, Johnson RG, Schrack RA (1984) Nucl Technol 67:162-168

9. Chichester DL, Sterbentz JW (2011) A second look at neutron resonance transmission analysis as a spent fuel NDA technique. INL/C0N-11-20783

10. Sterbentz JW, Chichester DL (2010) Neutron resonance transmission analysis (NRTA): a nondestructive assay technique for the next generation safeguards initiative's plutonium assay challenge. INL/EXT-10-20620

11. Kase T, Harada H (1997) Nucl Sci Eng 126:59-70 
12. Kitatani F (2013) 2013 Annual meeting of the Atomic Energy Society of Japan, A55

13. Ando Y, Takano H (1999) Estimation of LWR spent fuel composition. JAERI-Research 99-004

14. Uetsuka H, Nagase F, Suzuki T (1995) Gamma spectrometry of TMI-2 debris (in Japanese). JAERI-Research 95-084

15. Tsuchiya H, Harada H, Koizumi M, Kitatani F, Takamine J, Kureta M, Iimura H (2013) Nucl Instrum Methods Phys Res A 729:338-345

16. Tsuchiya H, Harada H, Koizumi M, Kitatani F, Takamine J, Kureta M, Seya M, Iimura H, Becker B, Kopecky S, Schillebeeckx P (2013) In: Proceedings of the 35th European Safeguards Research \& Development Association (ESARDA), Varese, Italy

17. Harada H, Kitatani F, Koizumi M, Tsuchiya H, Takamine J, Kureta M, Iimura H, Seya M, Becker B, Kopecky S, Mondelaers W, Schillebeeckx P (2013) In: Proceedings of the 54th European Safeguards Research \& Development Association (ESARDA), Varese, Italy

18. Schillebeeckx P, Abousahl S, Becker B, Borella A, Harada H, Kauwenberghs K, Kitatani F, Koizumi M, Kopecky S, Moens A, Sibbens G, Tsuchiya H (2013) In: Proceedings of the 35th European Safeguards Research \& Development Association (ESARDA), Varese, Italy

19. Becker B, Harada H, Kauwenberghs K, Kitatani F, Koizumi M, Kopecky S, Moens A, Schillebeeckx P, Sibbens G, Tsuchiya H (2013) In: Proceedings of the 35th European Safeguards Research \& Development Association (ESARDA), Varese, Italy

20. Schillebeeckx P, Becker B, Emiliani F, Kopecky S, Kauwenberghs K, Moens A, Mondelaers W, Sibbens G, Harada H, Kitatani F, Koizumi M, Kureta M, Iimura H, Takamine J, Tsuchiya H, Abousahl S, Moxon M (2013) In: Proceedings of the INMM 54th annual meeting European Safeguards Research \& Development Association (ESARDA), Varese, Italy

21. Tsuchiya H, Harada H, Koizumi M, Kitatani F, Takamine J, Kureta M, Iimura H, Becker B, Kopecky S, Kauwenberghs K, Moens A, Mondelaers W, Schillebeeckx P (2013) In: Proceedings of the INMM 54th annual meeting European Safeguards Research \& Development Association (ESARDA), Varese, Italy

22. Massimi C, Borella A, Kopecky S, Lampoudis C, Schillebeeckx P, Moxon MC, Vannini G (2011) J Korean Phys Soc 59:1689-1692 (and references therein)

23. Mughabghab SF (2006) Atlas Neutron Resonances. In: 5th ed Resonance Parameters and Thermal Cross Sections. $Z=1-100$, (2006, Elsevier Science)

24. Cote RE, Bollinger LM, Leblanc JM (1958) Phys Rev 111:288-295

25. Kapchigashev SV, Popov YP (1963) Atomnaya Energiya 15:120-126

26. Weigmann H, Winter J (1968) Z Physik 213:411-419

27. Alves RN, Barros SD, Chevillon PL, Julien J, Morgenstern J, Samour C (1969) Nucl Phys A 134:118-140

28. Julien J, Alves R, Barros SD, Huynh VD, Morgenstern J, Samour C (1969) Nucl Phys A132:129-160 